\title{
Radiotherapy with or without Concomitant Chemotherapy as Pre- or Post- operative Therapy in Non-small Cell Lung Cancer
}

\section{Hamdy D. Elayouty ${ }^{1 *}$ Ahmed M. Ba zaeb² and Abdulkader M. Bayazed ${ }^{3}$}

${ }^{1}$ Department of Cardiothoracic Surgery, Suez Canal University and Hadhramout University, Yemen, Egypt

${ }^{2}$ Oncology unit, Ben Sena Teaching Hospital, Hadhramout University, Almukala, Yemen, Egypt

${ }^{3}$ Department of Internal Medicine, Hadhramout University, Almukalla, Yemen, Egypt

\begin{abstract}
Introduction: Recently, it has been shown that in patients with unresectable non-small cell lung cancer, a short course of cisplatin and vinblastine prior to radiation significantly improves median survival and doubles the number of long- term survivors, as compared with radiation therapy alone. This combined strategy appears to produce a modest but definite improvement in unresectable lung cancer. Thus, the use of combined modality treatment in patients eligible for resection might have the ability to produce survival benefits.
\end{abstract}

Objectives: The goals are to assess the feasibility and toxicity of the combined regimen and to evaluate its ability to improve local control and quality of life by compressing the duration of treatment.

Methods: A randomized prospective pilot study using conventional radiation therapy with or without concomitant cisplatinum and etoposide as an adjuvant treatment in patients who have undergone resection as well as initial therapy for those with marginally resectable disease.

Forty two patients ( 25 men, 17 women) participated in this study. All patients had histopathologically proven non-small cell lung cancer. Their median age was 54 years (ranged between 33 and 63 years). No one experienced loss of appetite or significant weight loss. All patients had stage II B or IIIA disease.

Group A (21 patients): Those with marginally resectable disease received two cycles of chemotherapy preoperatively and a maximum of four cycles post-operatively. Patients with initially resectable tumors received four cycles postoperatively. Radiation therapy was begun on day 1 or 2 concomitantly with chemotherapy.

Group B (21 patients): They received radiotherapy without chemotherapy. Patients were equally distributed between both groups as regards the age, sex and tumor resectability.

Results: Group A (concomitant chemo-radiotherapy): Two patients developed marked degrees of toxicity severe enough to discontinue chemotherapy. They were shifted to the other group. The final number became 19 patients. Otherwise, the toxicity of chemotherapy was acceptable. Temporary discontinuation was necessary for fungal sinusitis in a diabetic case.

Group B: 21 patients increased to 23 after shift of these two from group A. One patient developed constrictive pericarditis, two pericardial effusions and one case had radiation pneumonitis.

Patients with initially resectable tumors underwent complete resection combined with either chemo-radiation therapy or radiation therapy alone, Eighteen out of 19 receiving cisplatinum and etoposide plus radiation remain alive at the end of therapy compared with 21 out of 23 patients of group B. First year survival rates among group A and group B were $84 \%(16 / 19)$ and $82 \%(19 / 23)$ respectively. Third year survival rates were $78 \%(15 / 19)$ and $62 \%(15 / 23)$. Five year survival rates were $68 \%(13 / 19)$ and $39 \%(9 / 23)$ respectively, $(P$ value $=0.001)$. Mean hospital stay for initial tri-modality treatment was shorter for patients in group $\mathrm{A}$.

Conclusion: Concomitant chemotherapy and radiotherapy regimen is feasible and reproducible. It is more effective as adjuvant treatment in non-small cell lung cancer than radiotherapy alone.

Keywords: Chemotherapy; Radiotherapy; Concomitant chemoradiotherapy; Bronchogenic carcinoma; Cisplatinum; Etoposide

\section{Introduction}

Most patients with non-small cell lung cancer have advanced disease at the time of initial treatment and only one third of patients are candidates for curative lung resection.

Treatment of advanced lung cancer has evolved from trials of postoperative adjuvant radiotherapy to postoperative chemotherapy to induction chemotherapy and induction chemo-radiotherapy [1].

In recent years, there has been increasing evidence that the use of concomitant chemotherapy and radiotherapy is feasible in the treatment of non-small cell lung cancer.

Recently, it has been shown that even in patients with unresectable stage III, a short course of cisplatin and vinblastine prior to radiation significantly improved median survival and doubled the number of long- term survivors, as compared with radiation therapy alone [2].

Our hypothesis was that tri modality therapy for lung cancer will

*Corresponding author: Dr. Hamdy D. Alayouty, Department of Chest Surgery, Suez Canal University Hospitals, Ismailia, Egypt, Tel: 002013-7271234/0020132720646; Fax: 0096705363022; E-mail: h.dosoky@yahoo.com

Received March 24, 2012; Accepted April 19, 2012; Published April 21, 2012

Citation: Elayouty HD, Ba Zaeb AM, Bayazed AM (2012) Radiotherapy with or without Concomitant Chemotherapy as Pre- or Post-operative Therapy in Non-small Cell Lung Cancer. J Cancer Sci Ther 4: 084-087. doi:10.4172/1948 5956.1000116

Copyright: (c) 2012 Elayouty HD, et al. This is an open-access article distributed under the terms of the Creative Commons Attribution License, which permits unrestricted use, distribution, and reproduction in any medium, provided the original author and source are credited. 
Citation: Elayouty HD, Ba Zaeb AM, Bayazed AM (2012) Radiotherapy with or without Concomitant Chemotherapy as Pre- or Post-operative Therapy in Non-small Cell Lung Cancer. J Cancer Sci Ther 4: 084-087. doi:10.4172/1948-5956.1000116

be reproducible and prolong symptom-free interval among patients with early cases of non-small cell lung cancer with a rate of toxicity and morbidity lower than the bimodality therapy (without chemotherapy).

\section{Objective and Rationale}

Current study represents the results of a randomized prospective pilot study using conventional radiation therapy with or without concomitant cisplatinum and etoposide as an adjuvant treatment in patients who had undergone resection as well as initial therapy for those with marginally resectable disease. Cisplatinum is a well-known and extensively studied radiation sensitizer. The combination of cisplatinum and etoposide has clear synergistic effects against a variety of human tumors and can produce a response rate of $30-40 \%$ in patients with non-small cell lung cancer [3]. The Eastern Cooperative Oncology Group reported that patients randomized to this combination had a modest but increased survival over patients treated with the other drug regimens [4].

The goals are to assess the feasibility and toxicity of the combined chemo-radiotherapy regimen and to evaluate its ability to improve local control and quality of life by shortening the duration of treatment.

\section{Methods}

This randomized prospective pilot study included 42 patients. 25 men and 17 women participated in this study. We received these patients at the Department of Chest Surgery- Suez Canal University Hospitals and Ben Sena Teaching Hospital-Yemen during the period from $1^{\text {st }}$ Mar 2005 through $29^{\text {th }}$ Feb 2008. Follow up continued for sixty months. Consent from patients and approval of The Ethics Committee were obtained.

All patients had not experienced neither decrease of appetite nor weight loss. Staging evaluation included bronchoscopy, bone scan, CT-scan of the chest, upper abdomen and brain. Invasive staging of mediastinal lymph nodes was performed as indicated by CT-scan. We used mediastinoscopy or mediastinotomy to biopsy lymph nodes having $1.5 \mathrm{~cm}$ or more in shortest diameter in stations 1 to 9 . All had histological diagnosis of non- small cell lung cancer. Their median age was 54 years (range: 33-63 years). Patients had stage IIB or IIIA disease. They were randomized to receive radiation or chemo-radiation therapy.

Patients with marginally resectable disease were randomized to receive radiation or chemo-radiation before possible surgery. They received two cycles of chemotherapy pre-operatively and a maximum of four cycles post-operatively. Patients with initially resectable tumors were randomized to receive four cycles of chemotherapy or radiotherapy postoperatively.

Radiation therapy was begun on day 1 or 2 concomitantly with chemotherapy or was given alone. Two patients discontinued chemotherapy and were added to group B. Initially Group A, included 21 patients after this shift, they became reduced to 19 patients. Group B: became 23 patients who received radiotherapy without chemotherapy. Patient characteristics are listed in Table 1.

All patients underwent pulmonary resection and had complete lymph node dissection. The latter was guided by computerized tomography of the chest and results of mediastinoscopy.

Chemotherapy, when given, consisted of cisplatinum $60 \mathrm{mg} / \mathrm{m}$. square on day 1 and etoposide $100 \mathrm{mg} / \mathrm{m}$. square on day 1,2 and 3 repeated at 21-28 day intervals, based on recovery of white blood count to a minimum of $4,000 / \mathrm{c} \mathrm{mm}$ and platelet count of $100,000 / \mathrm{c}$

\begin{tabular}{|c|c|c|}
\hline & $\begin{array}{c}\text { Chemo-radiation } \\
\text { (group A) }\end{array}$ & Radiation (group B) \\
\hline Final Number of patients & 19 & 23 \\
\hline Median age in years & 52 & 53 \\
\hline Male patients & 11 & 14 \\
\hline Female patients & 8 & 9 \\
\hline Histological types: & 12 & 14 \\
\hline Adenocarcenoma & 6 & 7 \\
\hline Squamous cell & 1 & 2 \\
\hline Large cell & 5 & 5 \\
\hline Stage: & 3 & 4 \\
\hline IIB (T2 N1M0) & 4 & 6 \\
\hline IIIA (T1N2M0) & 5 & 2 \\
(T2N2M0) & 1 & 1 \\
\hline (T3N0M0) & 1 & 9 \\
(T3N1M0) & & 8 \\
\hline (T3N2M0) & 7 & 4 \\
\hline Pulmonary resection: & 6 & 2 \\
\hline Lobectomy & 4 & $11 \pm 1.6$ \\
\hline Bilobectomy & 2 & \\
\hline Pneumonectomy & $9 \pm 2.1$ & \\
\hline Wedge resection (biopsy alone) & & \\
\hline Mean hospital stay in days & & \\
\hline
\end{tabular}

Table 1: Characteristics of patients.

$\mathrm{mm}$. Preventive use of G-CSF (granulocyte colony-stimulating factor) or GM-CSF (granulocyte macrophage colony-stimulating factor) was applied according to the guide lines described by the American Society of Clinical Oncology [5]. Updated guidelines for anti-emetics in oncology were applied [6]. Radiation therapy was given to both groups of patients $\mathrm{A}$ and $\mathrm{B}$, on day 1 or 2 concomitantly with chemotherapy or given alone. Treatment consisted of thirty-three $180 \mathrm{cGy}$ fractions (total dose, $5940 \mathrm{cGy}$ ) for patients receiving radiation alone in group B.

For those in group A, undergoing concomitant chemo-radiotherapy 30 fractions were given (5400 cGy total). Treatment was withheld if white blood cell counts were lower than $2000 / \mathrm{c} \mathrm{mm}$ or platelet levels were below 50,000/c mm. Individualized treatment planning employs lead shielding tailored to shape the field and limit the radiation exposure of normal tissues. Often the radiation is delivered from two or three different positions. Conformal three-dimensional treatment planning permits the delivery of calculated doses of radiation to the target mass without increasing complications in the transit volume.

Despite the small number of patients, the two groups were well matched for age, histological type and stage of tumor.

\section{Statistical Analysis}

The sample size was calculated according to Gay's equation: (multiplying thirty by number of variables Gay, 1980) and according to Freund \&Wilson equation. The variable is trimodality therapy versus bimodality therapy. The average flow of non-small cell lung cancer to our center is 1 to 2 cases per month, according to previous studies 5 -year survival rate is about 14 to $20 \%$ The accepted error $10 \%$, The Sample size according to Freund \&Wilson's equation $=(1.96 / 0.10)^{2}$ $(20)(70)=30$. According to Gays $=30 \times 1=30$. As some patients may be lost or become unable to complete the follow up, the study included 42 patients.

We used the mean, the percentage and the median values. SPSS program was used to apply bivariate analysis for correlation between method of treatment and survival on one side and modality of treatment 
Citation: Elayouty HD, Ba Zaeb AM, Bayazed AM (2012) Radiotherapy with or without Concomitant Chemotherapy as Pre- or Post-operative Therapy in Non-small Cell Lung Cancer. J Cancer Sci Ther 4: 084-087. doi:10.4172/1948-5956.1000116

and toxicity on the other side. Kaplan-Meier curves for survival were added (Figure 1).

\section{Results}

The toxicity of chemotherapy was acceptable, early discontinuation was indicated in two patients due to an anaphylactoid reaction, candida esophagitis, cardiac arrhythmia and patient refusal. Temporary discontinuation was necessary for fungal sinusitis in a diabetic patient who completed the therapy after a short time. Esophagitis and radiation pneumonitis required steroid therapy. Eighteen out of 19 patients who received cisplatinum and etoposide plus radiation were alive by the end of the therapy. They recorded a five-year survival rate of $68 \%$. Those who received adjuvant radiation, 21 out of 23 patients were alive by the end of therapy. One patient developed constrictive pericarditis and early pericardectomy was done. Two patients developed recurrent, rapidly accumulating pericardial effusion. Malignant cells were not detected in any one of these effusions. Thoracoscopic pericardial window was performed for each one. Another one developed Radiation pneumonitis.

They recorded 5-year survival rate of $39 \%$. The difference in survival rate between group A and group B was statistically significant. $(\mathrm{p}$ value $=0.001)$.

The rate of toxicity was generally low but severer among patients who had chemo.-radio therapy; the difference was statistically insignificant, Mean hospital stay was $9 \pm 2.1$ days for patients in group A while it was $11 \pm 1.6$ days among patients in group B (Table 2).

\section{Discussion}

Lung cancer remains the most common cause of death by malignancy in both men and women. Two thirds of the cases are resectable at presentation but resection is not curable in most of them. The diversity of molecular abnormalities in non-small cell lung cancer

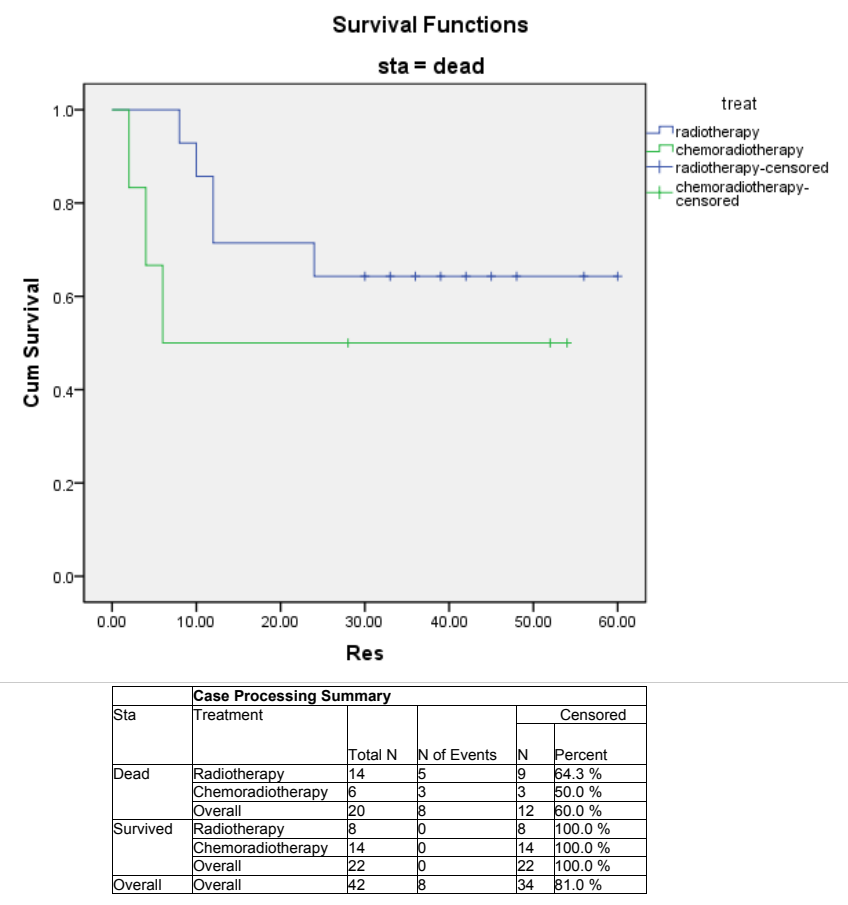

Figure 1: Kaplan-Meier curves.

\begin{tabular}{|c|c|c|}
\hline Patients & Group A & Group B \\
\hline No. & 21 & 21 \\
\hline $\begin{array}{c}\text { No. after severe toxicity of } \\
\text { chemotherapy }\end{array}$ & 19 & 23 \\
\hline Survivors at the end of therapy & 18 & 21 \\
\hline Mortality during therapy & $1(5 \%)$ & $2(8 \%)$ \\
\hline Five-year survival & $68 \%$ & $39 \%$ \\
\hline Toxicity of therapy: & \multicolumn{2}{|c|}{} \\
\hline - Anaphylactoid reaction, candida \\
esophagitis, cardiac arrhythmia
\end{tabular}

Table 2: The results.

may partly contribute to variable results of therapy. Also, adjustments in dosage of chemo- therapeutic agents or changes in radiotherapy planning could reduce toxicity and improve results [7].

Radiation therapy (Teletherapy) is a component of curative therapy for a number of diseases, including breast cancer, Hodgkin 's disease, head and neck cancer, prostate cancer and gynecological cancers. Radiation therapy can also, palliate disease symptoms in a variety of settings: relief of bone pain from metastatic disease, control of brain metastases, reversal of spinal cord compression and obstruction of superior vena cava, shrinkage of painful masses and opening of threatened airways [8]. Acute toxicities include skin erythema and ulceration and bone marrow suppression. These were alleviated among our patients by interruption of treatment. Chronic toxicities included pericardial effusions, chronic constrictive pericarditis and lung fibrosis interfering with efficiency of cardiac and pulmonary functions. They were minimized by proper planning of the radiotherapy. Recurrent rapidly accumulating pericardial effusion indicated pericardial window in two cases. Constrictive pericarditis indicated pericardectomy in one case.

Cisplatin was discovered fortuitously by observing that bacteria present in electrolysis solutions could not divide. Only the cis-diamine configuration is active as an antitumor agent. Cisplatin requires administration with adequate hydration, including forced dieresis with mannitol to minimize renal damage. In conventional doses, hearing loss is likely to develop in $50 \%$ of patients. Etoposide is one of the antitumor antibiotics. Toxic effects include myelosuppresion, nausea and transient hypotension related to the speed of administration [9].

Indications for the clinical use of G-CSF (granulocyte colonystimulating factor) \& GM-CSF (granulocyte macrophage colonystimulating factor) are both preventive and therapeutic. According to the American Society of Clinical Oncology preventive uses include:

1 -With the $1^{\text {st }}$ cycle of chemotherapy ( primary colony-stimulating factor administration).

- If the probability of febrile neutropenia is $\geq 20 \%$.

- If the patient is having neutropenia or active infection.

- Age is above 65, treated for lymphoma or other tumors, with curative intent. 
Citation: Elayouty HD, Ba Zaeb AM, Bayazed AM (2012) Radiotherapy with or without Concomitant Chemotherapy as Pre- or Post-operative Therapy in Non-small Cell Lung Cancer. J Cancer Sci Ther 4: 084-087. doi:10.4172/1948-5956.1000116

- Poor performance status.

- Extensive prior chemotherapy.

- Dose dense therapy.

2-With subsequent cycles if febrile neutropenia has previously occurred.

Anemia associated with chemotherapy can be managed by transfusion of packed red blood cells. Transfusion is not undertaken until the hemoglobin falls to $<80 \mathrm{gm} / \mathrm{L}(8 \mathrm{gm} / \mathrm{dL})$.

Current randomized prospective pilot study was designed to explore the feasibility of reproducing a regimen for delivering concomitant chemo-radiation using moderate dosage cisplatinum on day 1 plus etoposide on days 1,2 and 3 in 21-28 day cycles with a goal of 4 cycles of treatment along with radiotherapy. There are several theoretical reasons why a simultaneous approach would be advantageous. First, a situation where there are local recurrences and systematic metastases, there is the early delivery of each treatment modality- each with its independent activity. In the post-operative sitting, each treatment can be initiated within 6 weeks of surgery. This eliminates the concern that chemoradio-therapy administered before radiation might produce an unwelcome delay that could compromise local control or even produce resistance of the tumor cell to radiation. On the other hand, one of the arguments in favor of induction or neo-adjuvant chemotherapy is that initial radiation may alter tumor blood flow or decrease patient tolerance or sensitivity to chemotherapy $[10,11]$. Second, the toxicity profiles of the two modalities are sufficiently different to allow high doses of each in order not to compromise the effects of either. The toxicity of radiation is for the most part limited to the mediastinum and lungs. The side effects of chemotherapy often involve the bone marrow, the kidney and liver. Finally, cisplatinum and radiation have synergistic cyto-toxicity. Cisplatinum can generate free radicals that will enhance radiation and can inhibit repair of the damage caused by radiation, specially damage induced on DNA, RNA and protein cross-links. Enhanced survival with concomitant chemo-radiotherapy has been shown for patients treated in randomized studies for renal, pancreatic, colorectal, small cell lung, head and neck and cancer cervix. This is presumed to be due to improving local and systemic control, a decrease in radio-resistance and elimination of sites of early metastases [12] (Table 3).

Caution is required in drawing any conclusions regarding survival given the small size of our group of patients. Current study showed that the combined chemo-radiotherapy regimen proved its feasibility and reproducibility. It has the ability to improve local control and quality of life by shortening the duration of treatment.

\begin{tabular}{|l|c|c|c|}
\hline Survival & $\begin{array}{c}\text { Group A (tri modality } \\
\text { therapy) }\end{array}$ & $\begin{array}{c}\text { Group B (bi } \\
\text { modality therapy) no } \\
\text { chemotherapy }\end{array}$ & P value \\
\hline After start of therapy & $19(100 \%)$ & $23(100 \%)$ & \\
\hline By the end of therapy & $18(95 \%)$ & $21(91 \%)$ & \\
\hline $1^{\text {st }}$ year & $16(84 \%)$ & $19(82 \%)$ & \\
\hline $2^{\text {nd }}$ year & $16(84 \%)$ & $18(77 \%)$ & \\
\hline $3^{\text {rd }}$ year & $15(78 \%)$ & $15(62 \%)$ & \\
\hline $4^{\text {th }}$ year & $15(78 \%)$ & $11(44 \%)$ & \\
\hline $5^{\text {th }}$ year & $13(68 \%)$ & $9(39 \%)$ & \\
\hline 5 5-year survival rate & $68 \%$ & $39 \%$ & \multirow{2}{*}{0.001} \\
\hline
\end{tabular}

Table 3: Survival among both groups.

\section{Conclusions}

Concomitant cisplatinum, etoposide and radiation therapy regimen is feasible and reproducible. It is more effective as adjuvant treatment in non-small cell lung cancer than postoperative radiotherapy alone.

\section{Acknowledgement}

Prof. Sohair abd Almohsen, Professor of Oncology for her great help.

\section{References}

1. Daly BD (1999) Late results. Chest Surg Clin N Am 9: 675-693.

2. Dillman RO, Seagren SL, Propert KJ, Guerra J, Eaton WL, et al. (1990) A randomized trial of induction chemotherapy plus high-dose radiation versus radiation alone in stage III non-small-cell lung cancer. $\mathrm{N}$ England J Med 323: 940-945.

3. Klastersky J (1986) Therapy with cisplatin and etoposide for non-small-cell lung cancer. Semin Oncol 13: 104-114.

4. Ruckdeschel JC, Finkelstein DM, Ettinger DS, Creech RH, Mason BA, et al (1986) A randomized trial of the four most active regimens for metastatic nonsmall-cell lung cancer. J Clin Oncol 4: 14-22.

5. Smith TJ, Khatcheressian J, Lyman GH, Ozer H, Armitage JO, et al. (2006) 2006 update of recommendations for the use of white blood cell growth factors: an evidence-based clinical practice guideline. J Clin Oncol 24: 3187-3205.

6. American Society of Clinical Oncology, Kris MG, Hesketh PJ, Somerfield MR Feyer P, et al. (2006) American Society of Clinical Oncology guideline for antiemetics in oncology: update 2006. J Clin Oncol 24: 2932-2947.

7. Arrieta O, Gallardo-Rincón D, Villarreal-Garza C, Michel RM, Astorga-Ramos AM, et al. (2009) High frequency of radiation pneumonitis in patients with locally advanced non-small cell lung cancer treated with concurrent radiotherapy and gemcitabine after induction with gemcitabine and carboplatin. J Thorac Onco 4: 845-852.

8. Rusch VW, Giroux DJ, Kraut MJ, Crowley J, Hazuka M, et al. (2001) Induction chemoradiation and surgical resection for non-small cell lung carcinomas of the superior sulcus: Initial results of Southwest Oncology Group Trial 9416 (Intergroup Trial 0160). J Thorac Cardiovasc Surg 121: 472-483.

9. Sausville EA, Longo DL (2008) Principles of cancer treatment in Harrison's Internal Medicine (17 $7^{\text {th }}$ Edn), The McGraw-Hill Companies, Inc 1: $514-532$

10. Clark I, Fallon B, Frei E (1987) Induction chemotherapy as initial and treatment for advanced head and neck cancer a model for the multidisciplinary treatment of solid tumors. In Important Advances in Oncology V De Vita. S Hellman and Rosenberg S (Eds) Philadelphia IB Lippincott 175-196.

11. Byfield JE, Stanton W, Sharp TR, Frankel SS, Koziol J (1983) Phase I-II study of 120 -hour infused 5-FU and split-course radiation therapy in localized nonsmall cell lung cancer. Cancer Treat Rep 67: 933-936.

12. Vokes EE, Weichselbaum RR (1990) Concomitant chemoradiotherapy: rationale and clinical experience in patients with solid tumors. J Clin Oncol 8 : 911-934. 